\title{
Successful surgical repair of left ventricular pseudoaneurysm in a patient with subacute ST-elevation myocardial infarction
}

\author{
Rosangela Cocchia $^{1}$, Gabriele Iannelli ${ }^{2}$, Valentina Capone ${ }^{1}$, Salvatore Chianese ${ }^{1}$, Giuseppina Langella ${ }^{2}$, \\ Brigida Ranieri ${ }^{3}$, Massimo Majolo ${ }^{4}$, Giuseppe Russo ${ }^{4}$, Emanuele Pilato ${ }^{2}$, Ciro Mauro ${ }^{1}$, Eduardo Bossone ${ }^{1}$ \\ ${ }^{1}$ Cardiology Unit, Internal Medicine Department, Antonio Cardarelli Hospital, Naples; ${ }^{2}$ Division of Cardiac Surgery, \\ Department of Advanced Medical Sciences, University of Naples "Federico II", Naples; ${ }^{3}$ Imaging Department, IRCCS \\ SYNLAB SDN, Naples; ${ }^{4}$ Health Management Office, Department of Strategic Services in the Medical Area, Antonio \\ Cardarelli Hospital, Naples, Italy
}

\begin{abstract}
We report a successful surgical repair of left ventricular pseudoaneurysm in a patient with subacute ST-elevation myocardial infarction (STEMI). In the case of expansion of the infarct related ventricular wall, early (within 24 hours) or late (3-5 days after STEMI) cardiac rupture should be always borne in mind in order to proceed to life saving prompt surgical repair.
\end{abstract}

\section{Introduction}

Cardiac rupture occurs in $1 \%$ to $6 \%$ of all patients admitted with subacute ST-elevation myocardial infarction (STEMI) [1]. It should be considered for urgent cardiac surgical repair [1].

Correspondence: Eduardo Bossone, Cardiology Division, Antonio Cardarelli Hospital, Via A. Cardarelli 9, 80131 Naples, Italy.

Tel. + Fax +39.081.7473068

E- mail: eduardo.bossone@aocardarelli.it

Key words: left ventricular pseudoaneurysm; surgical repair; STEMI

Contributions: CM, EB, study design; RC, GI, VC, SC, GL, BR, MM, GR, EP, CM, EB, data acquisition and analysis, manuscript drafting and revision. All the authors have read and approved the final version of the manuscript and agreed to be accountable for all aspects of the work.

Funding: This research received no specific grant from any funding agency in the public, commercial, or not-for-profit sectors.

Conflict of interest: The authors declare that they have no competing interests, and all authors confirm accuracy.

Received for publication: 15 July 2021.

Accepted for publication: 4 August 2021.

${ }^{\mathbb{C}}$ Copyright: the Author(s), 2021

Licensee PAGEPress, Italy

Monaldi Archives for Chest Disease 2022; 92:2016

doi: 10.4081/monaldi.2021.2016

This article is distributed under the terms of the Creative Commons Attribution Noncommercial License (by-nc 4.0) which permits any noncommercial use, distribution, and reproduction in any medium, provided the original author(s) and source are credited.

\section{Case Report}

A 65-year-old man was admitted to the emergency department for abdominal pain begun 4 days before. Past medical history consisted of ischemic stroke and diabetes mellitus. Of note, he was not taking any medication. Vital signs: blood pressure 90/50 $\mathrm{mmHg}$, heart rate $50 /$ minute, respiratory rate $18 /$ minute, body temperature $36.5^{\circ} \mathrm{C}$; saturation oxygen level $93 \%$. High-sensitivity cardiac troponin was mildly elevated (121 $\mathrm{pg} / \mathrm{mL})$. Electrocardiogram showed sinus bradycardia, Q waves with ST elevation in antero-lateral leads consistent with subacute STEMI. Transthoracic echocardiogram (TTE) revealed aneurysmatic expansion of apical left ventricular (LV) walls (ejection fraction $30 \%)$ with a large apical thrombus $(35 \times 15 \mathrm{~mm})$ [2]. Coronary angiography showed complete occlusion of proximal left anterior descending artery and a critical stenosis of right coronary artery; percutaneous coronary intervention with stent implantation on right coronary artery was performed. He received triple antithrombotic therapy with aspirin, clopidogrel, intravenous heparin first and then oral anticoagulation with warfarin [2,3]. During coronary care unit stay, the patient was asymptomatic and hemodynamically stable. However, a control TTE (day 6) in cardiology ward revealed the presence of pseudoaneurysm with an oval out-pouching $(23 \times 13 \mathrm{~mm})$ from the apical aspect of LV septum, communicating with the LV chamber through a passage measuring $1.6 \mathrm{~cm}$. Partially organized pericardial effusion was evident around right ventricular free wall (Figure 1). Thus, the patient was immediately transferred to the cardiac surgery department for urgent surgical repair [1]. The LV anterior wall rupture with pseudoaneurysm was then treated with endoaneurysmectomy of the LV with dacron patch and freewall reconstruction with prolene sutures and teflon felt stripes (Figure 2).

The patient was finally discharged 3 weeks after surgery with betablockers, ACE-inhibitors, diuretics, statins and dual antiplatelet therapy with aspirin and clopidogrel. At one month follow-up visit, the patient was hemodynamically stable with acceptable functional capacity.

\section{Discussion}

LV pseudoaneurysms (rare clinical and anatomopathological entity) occur when cardiac rupture is contained by adherent pericardium or scar tissue. Most common aetiology is myocardial 

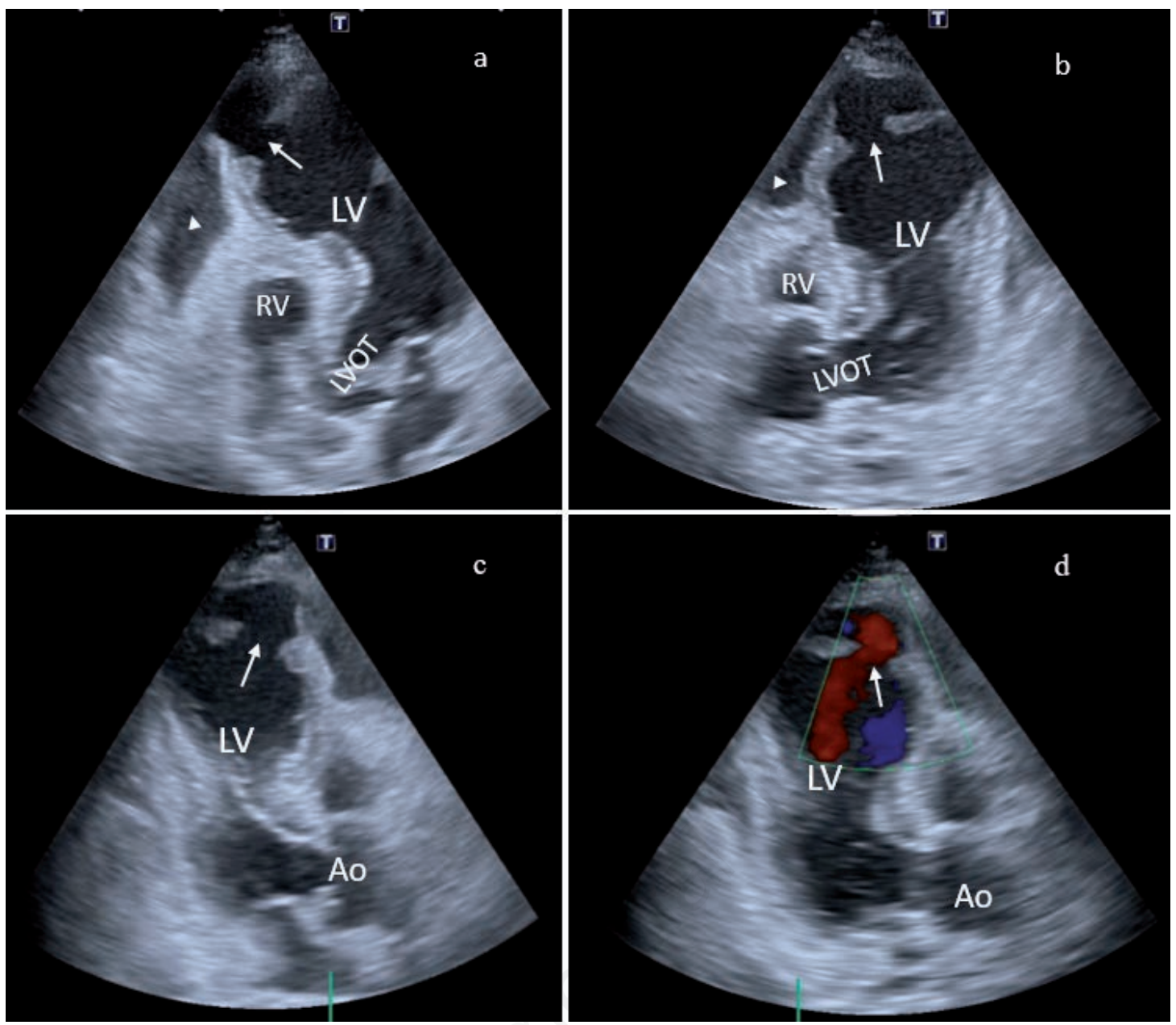

Figure 1. Modified five chamber view (a,b) and three chamber view (c,d) showing apical LV pseudoaneurysm (arrows) with moderate pericardial effusion (arrowhead); color Doppler through the passage (arrow) in 3 chamber view (d). Ao, aorta; LV, left ventricular; LVOT, left ventricular outflow tract; $R V$, right ventricle.
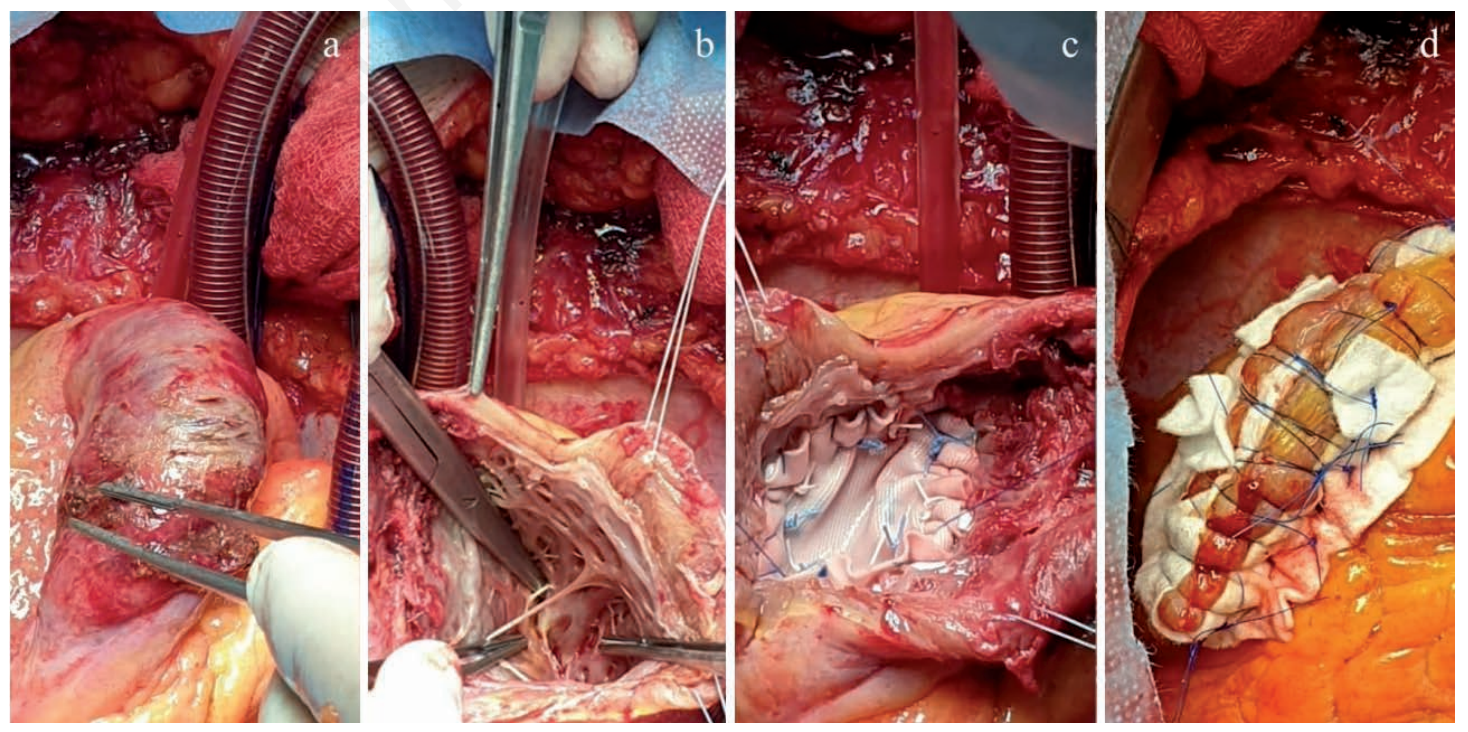

Figure 2. Steps of the surgical repair: the pseudoaneurysm (a), the LV chamber after pseudoaneurysm excision (b) and the ventriculoplasty $(c, d)$. LV, left ventricular. 
infarction. Due to non specific symptoms the diagnosis is challenging (up to $10 \%$ of patients can be asymptomatic) [4]. Echocardiography is considered to be the first line diagnostic imaging. Cardiac MRI remains an additional valid option if specific anatomo-functional details are needed.

\section{Conclusions}

In the case of expansion of the infarct related ventricular wall, early (within 24 hours) or late (3-5 days after STEMI) cardiac rupture should be always borne in mind in order to proceed to life saving prompt surgical repair [3]. However surgical mortality rate remains high (up to $60 \%$ ) [5].

\section{References}

1. Antman EM, Anbe DT, Armstrong PW, et al. ACC/AHA guidelines for the management of patients with ST-elevation myocardial infarction executive summary. A report of the American College of Cardiology/American Heart Association Task Force on Practice Guidelines (Writing Committee to revise the 1999 guidelines for the management of patients with acute myocardial infarction). J Am Coll Cardiol 2004;44:671-719.

2. Ibanez B, James S, Agewall S, et al.. 2017 ESC Guidelines for the management of acute myocardial infarction in patients presenting with ST-segment elevation: The Task Force for the management of acute myocardial infarction in patients presenting with ST-segment elevation of the European Society of Cardiology (ESC). Eur Heart J 2018;39:119-77.

3. Wong GC, Welsford M, Ainsworth C, et al. 2019 Canadian Cardiovascular Society/Canadian Association of Interventional Cardiology Guidelines on the Acute Management of STElevation Myocardial Infarction: Focused Update on Regionalization and Reperfusion. Can J Cardiol 2019;35:107-32.

4. Frances C, Romero A, Grady D. Left ventricular pseudoaneurysm. J Am Coll Cardiol 1998;32:557-61.

5. McMullan MH, Maples MD, Kilgore TL Jr, Hindman SH. Surgical experience with left ventricular free wall rupture. Ann Thorac Surg 2001;71:1894-8; discussion 1898-9. 